\title{
Research and Practice on the Quality Construction of Free Elective Courses in Colleges and Universities
}

\author{
Xiaobo Zhang \\ School of Computer, Xianyang Normal University, Xianyang, China
}

Email address:

zhangxiaobo419@126.com

\section{To cite this article:}

Xiaobo Zhang. Research and Practice on the Quality Construction of Free Elective Courses in Colleges and Universities. Science Innovation. Vol. 9, No. 5, 2021, pp. 189-193. doi: 10.11648/j.si.20210905.12

Received: September 4, 2021; Accepted: September 26, 2021; Published: September 30, 2021

\begin{abstract}
Curriculum construction is the key to the quality of undergraduate teaching, and the free elective course is the expansion of professional knowledge. Free elective courses in colleges and universities are courses that can be independently selected by students according to their individual differences outside the professional courses. It is a necessary supplement and expansion of professional knowledge. Gold course construction refers to the first-class curriculum construction implemented by the Ministry of education, which aims to build a high-level curriculum with high-level, innovative, challenging and other attributes. The construction of golden course plays an important role in the curriculum construction of colleges and universities While striving to build national first-class courses and provincial first-class courses established by the Ministry of education, colleges and universities are also actively building school-class golden courses to comprehensively improve the quality of curriculum construction. However, at present, gold class construction usually emphasizes professional courses curriculum construction. Based on the author's teaching practice and management experience, this paper expounds the importance of the construction of gold free elective courses and the way of construction. This paper emphasizes that the gold free elective course has the characteristics of flexible content selection, close connection with practice, close combination with the second classroom, innovation and entrepreneurship, etc. To create an elective free gold course, one can start from the aspects of teacher selection, classroom organization, teaching evaluation, free elective course management, etc, and strive to improve the quality of free elective courses and the participation of students, so as to make it an important link in the cultivation of high-quality talents.
\end{abstract}

Keywords: Free Elective Course, Gold Course, The Second Classroom, Innovation and Entrepreneurship, Teaching Evaluation

\section{高校任选课金课质量建设的探索与实践}

张小波

咸阳师范学院计算机学院, 咸阳, 中国

邮箱

zhangxiaobo419@126.com

摘要：课程建设是大学本科教学质量的关键。学校任选课是在专业课之外, 根据学生个体差异, 设置的可供学生自主 选择的课程, 是专业知识的必要补充和拓展。金课建设, 即金牌课程建设, 是指教育部实施的一流课程建设, 旨在建 设具有高阶性、创新性、挑战度等属性的高水平课程。金课建设在高校课程建设中起着提纲挈领的作用。各高校在力 争建设教育部设立的国家级一流课程和省级一流课程的同时, 也在积极建设校级金课, 全面提升课程建设质量。然而 在当前, 金课建设通常强调的是专业课课程建设。笔者从自身的教学实践及管理经验出发, 阐述学校任选课金课建设 的重要性和任选课金课建设的方式。本文强调任选课金课具有内容选取灵活且密切联系实际、与第二课堂及创新创业 
等紧密结合的特征, 打造任选课金课可从师资选择、课堂组织、教学评价、任选课管理等方面着手, 着力提升任选课 课金课品质和学生参与度, 使任选课成为高素质人才培养中的重要一环。

关键词: 任选课, 金课, 第二课堂, 创新创业, 教学评价

\section{1. 引言}

2018年5月2日,习近平主席在北京大学师生座谈会上 强调,教育兴则国家兴,教育强则国家强。2018年8月, 教育 部发布《关于狠抓新时代全国高等学校本科教育工作会议 精神落实的通知》, 要求全面整顿教育教学秩序, 严格本 科教育过程管理。该通知对课程建设提出明确要求, 要求 各高校要全面梳理各门课程的教学内容, 淘汰“水课”、打 造“金课”, 依据实际情况提升学业挑战度、增加课程难度、 拓展课程深度 $[1,2]$ 。

目前,从教育部到地方高校已建立金课建设体系。金 课包括包括线下“金课”、线上“金课”、线上线下混合式“金 课”、虚拟仿真“金课”和社会实践“金课”五大类型。从层次 上讲, 金课有国家级金课, 比如双万计划要求建设 1 万门 国家级一流线上线下的精品课程, 金课有省级金课, 比如 双万计划要求打造 1 万门省级一流线上线下的精品课程 [3], 除此之外, 各高校也在积极建设符合自身特色的校级 金课。从覆盖面上讲, 在2018年11月24日第11届中国大学 教学论坛上, 教育部吴岩司长指出, 各个专业都应有“金 课”, “金课”应涉及公共课“金课”、专业课“金课”、培养“创 新型”人才的“金课”、培养“复合型”人才的“金课”、培养“应 用型”人才的“金课”, “金课”应异彩纷呈、多种多样，符合 学生需求。

大学传统的课程设置主要包含专业课和选修课。选修 课有专业限选课和学校任选课。专业限选课与专业联系紧 密, 在专业课架构体系之中。然而, 金课建设要求门类全 覆盖, 全方位满足人才培养需求。但是, 关于任选课金课 的建设并未受到足够的重视。学校任选课是在专业课之外, 根据学生个体差异, 设置的可供学生自主选择的课程。“大 学金课”建设是本科教育教学质量提高、人才培养质量和水 平提高的关键举措, 通常的金课课程建设, 关注的是专业 课, 事实上, 任选课在学生差异化成才中具有重要作用。

建设任选课金课, 首先必须明确任选课课金课具有怎 样的属性。任选课金课首先是“金课”。如前所述, “金课” 本质上是高质量课程的统称。“金课”是相对于“水课”而 言, 当一堂课的含金量达到一定程度, 就可以称之为“金 课”。吴岩司长认为金课应具有“两性一度”, 即高阶性、 创新性、挑战度。“高阶性”, 指知识能力素质的有机融合, 应该培养学生解决复杂问题的综合能力和高级思维。“创 新性”, 是课程内容应反映前沿性和时代性, 教学形式呈 现先进性和互动性, 学习结果具有探究性和个性化。“挑 战度”, 指课程应有一定难度, 需要跳一跳才能够得着, 对老师备课和学生课下均有较高要求。

因此，任选课金课天生具有的“两性一度”属性要求任 选课“金课”建设过程中, 仍需以课堂为核心, 强调充分的 师生互动。任选课“金课”课堂应满足学生高度旺盛的求知
欲, 强化学习者有效参与、学习内容恰当、教学评价符合 实际三原则。教学过程中, 教师必须真正关注学生成长, 坚持“成长比成功更重要”、“成长是最大的成功”的教学理 念。任选课金课建设过程中, 应强调教师教学的自主权, 使教师成为富于教学创新的教育者, 主动融入学术共同体 和教学共同体, 积极参与学科建设和科学研究, 提升自身 专业素养、提升自己的教学水平, 并与行政共同体相处融 洽, 促使学生充分发挥主观能动性, 增强学习能力, 实现 自我发展, 从而形成良好的教风和学风, 促使金课更金。 笔者将结合学校任选课《图像处理的基本方法》阐述任选 课金课建设的几个方面

\section{2. 任选课金课的特征}

学校任选课具有比专业限选课更大的选课自主权。学 校任选课比专业限选课在选修课体系中更具一般性。学校 任选课是高校用以拓宽、加深学生知识结构, 并满足学生 个人兴趣、爱好的课程, 既能体现人才培养的全面性, 也 给予学生在学业和综合发展方面的充分选课自主权, 是学 生自我发展自我设计的重要平台, 也是度量大学教学质量 的重要环节[4]。设计和教授学生喜爱的任选课金课, 首先 要明确任选课金课应该具有哪些特征。

\section{1. 内容选取}

任选课的特征之一表现在内容选取方面。任选课的内 容选取要与专业课互补, 专业课大多都是基础性课程, 就 计算机类专业而言, 比如《高等数学》、《数据结构》、 《软件工程》等都是很成熟的课程, 以及电子信息类课程 《图像处理》等也是介绍一些图像处理领域的基本知识, 而作为任选课的《图像处理的基本方法》针对的是大学理 工科学生, 尽管它也强调基础性方法的阐述, 但是角度不 同, 首先, 它面向的学习对象更具宽泛性。因此, 它须针 对地方本科院校的学生特点, 尤其是本校学生的特点, 具 有更好的适应性。地方本科院校的学生数学功底相对较 差, 而图像处理的学习要求一定的数学基础知识, 因此知 识讲授的切入点要恰当。在针对本校学生选用数学类教材 的情况和数学学习调研的基础上, 开设的《图像处理的基 本方法》分为两大部分, 第一部分为数学基础, 第二部分 为图像处理方法。数学基础以大学数学为基础, 即《高等 数学》、《线性代数》、《概率统计》等课程的重要知识 点为基础, 第二篇以第一篇的基础知识点为基础, 基于授 课教师的系列科研成果展开图像处理基本方法的讲授, 让 学生领略数学的鬼力, 热爱数学、热爱数学的应用、热爱 图像处理学科。即内容选取要基于学生特点和师资特点, 在学生可接受、教师有成果的基础上, 具有针对性的拓宽 学生的知识结构。 


\section{2. 第二课堂}

任选课应与第二课堂紧密结合。第二课堂与第一课堂 相比,具有参与主体的主动性、时间地点的自由性、方式 方法的多样性、内容丰富性等特点, 是第一课堂的延伸和 补充。第二课堂在培养学生创新能力、实践能力, 开阔学 生的科学视野和广泛的兴趣爱好,坚定学生理想信念等方 面有重要作用。但是, 目前第一、第二课堂联系不够紧密 [5-8]。调研中发现,高校第二课堂活动较多,但往往偏重于 文体娱乐型活动,结合专业的理论研究、科技创新活动相 对欠缺,特别是高水平的具有一定科研影响的社会实践活 动较少, 学生利用所学知识去解决生产实际和生活实际中 的问题的能力培养不够, 学生参与社会实践专业特色不够 突出,理论到实践再到理论的良性循环教育模式尚未完全 建立。

而任选课课正好可以架起第一课堂与第二课堂之间 的桥梁。以《图像处理的基本方法》为例, 通过该门选修 课的学习, 可以扩展理工类专业学生的知识面, 提高学生 运用所学知识解决问题的能力。学生可参加各类图像处理 方面的竞赛和科技活动, 从而使第一课堂和第二课堂形成 闭环。

\section{3. 创新训练}

创新创业教育依托专业培养, 以课程体系为支撑。课 程体系的构建需具有层次多样、修读方式多样、开设方式 灵活等特征, 包括必修, 选修等。任选课作为其中重要一 环,具有不可替代的作用 $[6,9,10,11]$ 。

任选课金课应聚焦于自学能力的提高, 聚焦于科学研 究能力的提升, 以创新创业为抓手, 使任选课具有高阶性、 挑战性。

开设自然科学类任选课, 培养学生的兴趣, 弥补学生 常规课堂期间知识积累的不足, 培养学生创新创业意识。 创新意识的产生, 需要授课教师潜移默化, 从理念和思想 方面向学生灌输创新创业意识, 在学生的脑海中播下创新 创业的种子, 以激发学生的创新潜能, 引导学生勇于批判, 开拓思维, 改变僵化的思维模式。

在任选课中强调创新意识的培养, 也是大众创业、万 众创新的必然要求。学校任选课的设置打破了学院、学科 及专业的界限, 更易于产生创新的火花; 把创新教育环节 融入到相关任选课中, 让学生汲取最前沿的知识和信息, 是一种自然而然的行为。通过任选课的教育环节, 实现学 生自主设计、创新创业技能素质提升的目标。

\section{3. 如何打造选修课金课}

\section{1. 师资的选择}

师资的选取是任选课金课建设的关键，课堂是由教师 主导的，授课教师的素质决定着任选课金课的质量。

关于授课教师的选择，首先应关注授课教师的师德。 2016年12月习近平总书记在全国高校思想政治工作会议 提出的“四个统一”, 用以加强师德师风建设。四个统一, 即坚持教书和育人相统一，坚持言传和身教相统一，坚持
潜心问道和关注社会相统一, 坚持学术自由和学术规范相 统一 [12]。习近平总书记要求广大教师以德立身、以德立 学、以德施教。作为金课授课教师, 应以德为先, 输出正 能量, 在教学过程中形成积极向上的教学氛围。

具备了良好的师德, 根据前述对任选课金课的特征描 述。任选课主讲教师还应该是教学科研并重型的教师。教 师的责任在传道、授业、解惑, 这是自古以来, 社会对教 师的传统要求。作为新阶段中国特色社会主义新时代的高 校教师, 除了教学, 还承担着创造科学知识的重任。即, 高校教师有教学和科研的双重责任, 两者均不可偏废。

教师在科研中, 形成了自己的研究专长, 身处于一定 的学术团队中, 既有独立从事科学研究的能力, 又有团结 协作的经验, 经历了学术科研创新的全过程, 并以自己在 长期教学活动中形成的的教学专长, 言传身教, 更易寻找 学生的潜能和学力的发展点, 激发学生的学习兴趣, 点燃 学生的创新火花, 使学生在在学习活动中, 实现“长处更 长”的发展潜能目标。

此外, 为了更好引导培养学生, 教师本身需要良好的 性格, 人生态度积极, 乐观向上, 与教师和行政人员相处 融洽, 能够积极主动为自己营造一个良好的科研教学生活 环境。

\section{2. 任选课金课的课堂教学组织}

任选课金课的打造, 离不开课堂教学, 课堂教学是高 等学校教学的主阵地。如何有效的对课堂进行组织, 使选 任选课成为第一课堂和第二课堂之间的纽带, 十分重要。 笔者认为任选课的课堂教学组织分为课堂教学组织和课 外教学引导两大类。

课堂组织中, 主讲教师应注重师生互动, 强调学生自 信的养成。针对地方本科生的数学水平, 有的放矢, 及时 调整授课方法。总体而言, 因为地方本科院校学生的整体 情况, 讲解数学知识时, 应深入浅出, 注重思想的传授。 课堂教学中要注重小组讨论, 这样将会使课堂教学组织更 加灵活, 对学生的引导更为自然。学校每年都会获批一定 数量的校级、省级、国家级大学生创新创业训练项目, 每 年都有学生获得互联网+等大赛的奖项。这些项目中有一 定数量的项目是与图像处理直接相关的, 授课教师可选择 一些项目, 进行讨论, 回归到课堂, 回归到第一课堂, 让 学生感受到第一课堂的重要性。课堂教学中, 任选课主讲 教师应鼓励学生积极参加开放实验、学术类社团活动, 拓 展自己的知识和能力结构。任选课主讲教师应给予学生尽 可能的引导和帮助, 增进师生情谊, 从而建立起以学生为 中心的“深度学习”的“和谐课堂”教学理念, 使学生自觉地 担负起学习的责任, 学得深、想得透。大学的深度学习指 向学术性知识而非常识性知识, 是学生深度思考和高阶思 维的过程。一定数量的讨论式教学将使教师更为全面深入 的了解学生, 教学过程中, 尽可能做到点面结合, 因材施 教, 使学生从内心喜欢任选课, 有获得感, 喜欢钻研。教 师也会因为与学生的交流, 因为学生成绩而有教书育人的 成就感[13]。 
此外, 课堂教学中, 主讲教师应紧密结合相关的大学 生创新训练项目、互联网+大赛等科技创新实践活动, 对 任选课的课外活动进行积极引导。

\section{3. 任选课的教学评价}

为把任选课打造成金课, 必须对教师和学生有所激励 和约束。教学评价应该由三部分组成: 教师评学、学生评 学、管理者评学。

教师评学, 由教师自评和教师评学生两部分组成。教 师自评, 主要是授课教师要在每一节课后自省, 不断总结 经验教训, 提升授课效果。事实上, 一节课讲的好不好, 教师最具发言权, 如果教师准备充分, 那么在授课中, 必 然会达到某种兴奋点, 这是教师授课的一种较高的境界。 最需要说明的一点是, 教学师评学中, 教师要深入浅出的 去授课。校任选课学生来自于不同专业, 基础不一, 授课 中, 需注意思想方法的传授, 基于此, 深入课程教学, 把 握授课深度, 充分调动学生。教师评学生过程中, 应注重 学生的参与度等。学生在课堂上的表现是否积极, 是疲于 应付还是主动思考, 学生基础怎么样, 接受的如何等, 在 课堂内外与学生的交流中, 教师要充分把握这些, 方能做 到心中有数, 因材施教。

学生评学, 由学生自评和学生评老师两部分组成。学 生自评过程中, 应注意剖析自身的学习动力, 该门课程与 自己的期望值差距, 自己是否有从事相关的第二课堂活动 和创新训练活动愿望和经历。学生评老师的过程中, 应注 重教师的师德、才学、课堂投入等方面的优点和不足。

管理者评学, 其评价主体主要有各级领导及教学管理 人员等; 从评价内容上来看主要是考察教师素质、教态、 教学内容、教法和教学效果等方面; 从评价形式和过程来 看, 主要是通过日常教学规范性检查、督导听课; 从评价 结果来看, 是将各考核内容分解成各级指标进行打分量化 考核, 然后将考核结果与职称评定和绩效工资等进行挂 钩。管理者评学中, 通行做法会将学生考试成绩作为关键 一环, 对于任选课, 笔者认为, 考试成绩固然可以在一定 程度上反映学生的学习态度和学习水平, 但是任选课金课 的目标是学生学习能力和创新创业能力的提升, 因此学生 在大学生创新训练项目、互联网+大赛等竞赛和科技活动 中的成绩是评价中更为关键的一环。这一环节较为客观, 也更能体现任选课金课的价值。

总之, 关于任选课金课的教学评价中, 教师评学和学 生评学, 以及教师和学生评学的交互, 是一种提高任选课 金课的主观行为, 也只有充分尊重学生和授课教师的“学” 与“教”的自主权, 教师和学生才能充分发挥主观能动性, 为构建任选课金课奉献自己的智慧 $[14,15]$ 。管理者评学对 于保障正常的教学秩序保驾护航, 对金课建设的相关主体 进行约束, 使得教学评价更为客观, 能更好促进金课的建 设和发展。

\section{4. 任选课的管理}

学校任选课, 通常是由教务处管理的。开设课程之前, 教务处会向各学院征集任选课课源。以本校为例, 征集课 程时, 通常会要求授课教师明确学生选课范围及条件以及
内容简介, 供学生选课时参考。但是, 在学生选课过程中, 因为缺乏指导, 学生重视程度不够, 没有经验, 选课时, 仅看课程名字, 而未仔细阅读课程简介, 以至于所选课程 与自己基础相差甚远。因此在任选课管理中, 必须强调学 生选修课程的过程, 需由二级学院组织, 授课教师讲解, 引起学生重视, 这是任选课管理中的第一个重要关键点。

人是有惰性的, 在任选课课程教学过程中, 教务处需 专门管理, 充分调动师生的主观能动性, 将任选课教学落 在实处。此外, 教务处需统筹安排课表事宜, 避免与学生 已有课程时间冲突。

针对任选课, 教务处也应组织针对任选课的教学竟赛 活动, 组织学校任选课课程展览, 激励教师基于自己的特 点开设任选课。教务部门, 应该在组织制定培养方案时, 充分考虑任选课的重要性。目前, 地方高校, 制定培养方 案时, 授课时数在减少。事实上, 部分未开课程可由教师 开设学校任选课, 补充完善学生知识结构。专业负责人可 在制定培养方案时, 全盘考虑, 基于专业培养目标优化课 程设置, 给出任选课建议课程, 避免部分学生盲目选课, 从而使任选课成为部分学生混学分的现象一去不复返。

\section{4. 结论}

为了拓宽学生的知识面和视野, 优化学生的知识结 构, 提高学生综合素质, 培养全面发展的高素质应用型创 新人才, 笔者根据自己的教学、科研、管理工作实际, 结 合任选课《图像处理的基本方法》，从任选课金课特征出 发, 强调任选课内容选取要基于学生特点和师资特点, 在 学生可接受、教师有成果的基础上, 具有针对性的选择任 选课素材, 授课时需注意与第二课堂和创新创业紧密结 合, 课堂组织要因材施教、有的放矢, 使任选课真正成为 第一课堂和第二课堂之间的纽带, 应基于学生学习能力和 创新创业能力提升这一视角加强教学评价, 可从学生合理 选课和调动教师教学积极性方面强化任选课的教务管理, 全面阐述了任选课金课建设的途径和方法, 明确了任选课 金课建设方向, 为进一步完善金课建设体系, 使金课更金 进行了有益的探索和实践。

\section{致谢}

本文为咸阳师范学院教育教学改革研究项目“关于校 级选修课《图像处理的基本方法》金课建设的研究” (编 号：2019Y012）和国家自然科学基金项目“基于统计信息 的非线性扩散图像去噪算法研究” (编号: 61401383) 以 及陕西省自然科学基础研究计划项目 “基于各向异性统计 刻画的图像去噪算法研究” (编号: 2021JM-518) 的阶段 性成果之一。

\section{参考文献}

[1] 邓忠波.大学课程中“水课”现象审视与“金课”建设进路 [J], 中国电化教育，2020，(4): 68-74。 
[2] 刘进, 林松月.什么是大学“水课”:概念范畴、关键特征与治 理方向 [J], 黑龙江高教研究, 2019, (9): 7-14。

[3] 刘强, 赵亮, 赵文涛, 王勇军.面向专业能力提升的本科 Web安全实践教学金课建设初探 $[\mathrm{J}]$, 实验技术与管理, 2020, 37(6): 167-171。

[4] 马浚锋, 罗志敏.什么是大学“金课”: 学生如是说 $[J]$, 江苏 高教, 2019, (5): 60-66。

[5] 高明.高等学校第二课堂建设研究[J], 唐山学院学报, 2010, 23(6):41-42。

[6] 黄海鹏.高校 “第二课堂”建设存在问题及对策 $\mathrm{J}]$,淮南职业 技术学院学报,2020,20(1):82-83。

[7] 黄本生, 范舟, 罗霞, 黄志宇, 王平.地方高校第二课堂培 养学生双创能力的改革探索 [J] , 大学教 育,2021,(2):184-186。

[8] 莫秋桂.第二课堂与第一课堂相衔接的育人育才机制研究 [J], 科教导刊(下旬刊),2020,(33):6-8。
[9] 刘媛媛,曾华, 高柏.地方高校创新创业教育与专业教育融合 路径的探索 [J],教育教学论坛,2021,(4):82-85。

[10] 马致明,奕静,杨勇,李海芳,地方高校计算机创新人才培养的 探索与实践 $[J]$,电脑知识与技术,2021,(36):97-98。

[11] 姚琳, 严嘉.创新创业教育与专业教育深度融合的路径研究 [J], 中国大学生就业, 2020，(13):52-58。

[12] 张小波.基于“教”与“学”和睦的教学保障体系建设 $[\mathrm{J}]$, 教育 教学论坛, 2018, (01): 185-186。

[13] 张小波, 龚彦忠. 高校教师素养提升路径与教学文化建设探 究 [J], 高教学刊, 2020,(31): 154-156。

[14] 宋云雁. 普通高等学校新型教学评价体系构建研究 [J], 高教 学刊, 2018, (23):41-43。

[15] 王竹立.论信息时代的“金课”[J],煤炭高等教育,2019, 37(3): 14-21。 